\title{
GROWTH HORMONES AS RELATED TO THE SETTING AND DEVELOPMENT OF FRUIT IN NICOTIANA TABACUM ${ }^{1}$
}

\author{
Robert M. Muir
}

Stubies of growth hormones in plants have revealed many interesting aspects of the problem of fruit development. That growth hormones have a causal relationship to fruit development was first demonstrated when Gustafson (1936) induced parthenocarpic fruit development in tomato, Petunia, Salpiglossus and pepper. Mature fruits without seeds were produced through the use of the growth promoting chemicals indoleacetic, indolepropionic, indolebutyric and phenylacetic acids applied to the cut style. Gustafson (1937) found that extracts of pollen can induce fruit development in many plants and that this effect is not specific. The results of investigations by Laibach (1932) established the close relationship of the effective substances in pollen extracts to the growth hormones. Extracts of pollen and also of animal tissues caused the gynostemium to swell in certain tropical orchids and promoted the growth in length of the oat coleoptile. These facts were the basis for an hypothesis advanced by Gustafson (1939) that growth hormones from the pollen grains and pollen tubes initiate the early stages of fruit development, and after fertilization the developing embryo provides additional growth hormones. This paper deals with direct measurements of the growth hormones in the style, ovary and pedicel of pollinated flowers.

Experimental methods.-The plant used in the experiments has been Nicotiana tabacum L., Lizard's Tail variety. It was found that flowers and fruit setting could be obtained continually by cutting back the flowering shoots on plants brought in from the field in October and kept in the greenhouse. The concentration of growth hormones was determined by placing the plant tissue on a block of agar and allowing the diffusion of the growth hormones into the agar to continue for several hours (Went, 1928), and the subsequent application of this block unilaterally to a deseeded Avena coleoptile using Skoog's (1937) modification of the standard Avena test method (Went and Thimann, 1937).

Pollinations were made at different times previous to the diffusion of the hormones. At the time that some flowers were pollinated, others had the tip of the style covered with small lead foil caps to prevent pollination, and these were used as controls. Only flowers which had the stigma receptive and the anthers in the process of dehiscing were used. The flowers were removed from the plants just before the experiment, and each group of pollinations was

1 Received for publication June 4, 1942.

The investigations reported here were carried out by the writer as an F. C. and Susan Eastman Newcombe Fellow in plant physiology and a Horace $H$. Rackham Predoctoral Fellow. The writer expresses his gratitude to Professor F. G. Gustafson for his suggestions and interest in the course of this study.

Papers from the Department of Botany of the University of Michigan, No. 815. treated as a unit in the diffusion of the hormones. Each pistil was divided into three parts: the ovary, and two equal lengths $(1.8 \mathrm{~cm}$.) of the style. The three portions of a single pistil were kept together throughout the experiment so that results for each individual pistil were obtained. Immediately upon excision, the basal cut surfaces of the portions were placed for five to ten minutes on moist filter paper to prevent their drying out until set upon the agar blocks which were $2.7 \mathrm{~mm}$. $\times 2.9 \mathrm{~mm}$. $\times 1.6 \mathrm{~mm}$. Small supports of copper wire were used to hold the segments of the style in a vertical position, and care was exercised to ensure the existence of a film of water between the cut tissue surface and the surface of the agar. One and one-half per cent agar was used in experiments 1 and 2. 'The weight of the ovaries forty-five to sixty hours after pollination was great enough to crush the agar blocks to some extent, therefore, 3 per cent agar was used in experiment 3. All diffusions were for a period of three hours in an Avena test darkroom at a temperature of $25^{\circ} \mathrm{C}$. and in the saturated atmosphere of a large petri dish. At the end of the diffusion period the plant tissues were removed and the agar blocks were applied unilaterally to the deseeded Avena coleoptiles. The curvatures of the coleoptiles, after five hours, are recorded in table 1 .

Both the styles that were used for the determination of growth hormones and others pollinated at the time of the experiment were dissected under a binocular dissection microscope; the cortex was removed from the style and stigma. The strands of conducting tissue and the pollen tubes were stained with aqueous solutions of magenta red and light green S.F. Yellowish, according to the procedure of Buchholz (1931) and the growth of the pollen tubes was observed.

Results and Discussion.-Groteth hormones as related to pollination and fertilization.-Table 1 shows that in only a few instances were appreciable quantities of diffusible growth hormones found in the styles or ovaries of unpollinated flowers. The small amounts and their infrequent occurrence are in striking contrast with the results for pollinated flowers. In the styles from flowers pollinated fourteen hours previous to the diffusion of the growth hormones in the first experiment, the pollen tubes had grown through the apical half of the style and a few millimeters into the basal half. Considerable quantities of growth hormones were obtained from both the apical and basal portions of the styles with those from the basal portions being somewhat larger. The quantities obtained from the ovaries were in most cases less than those from the styles at this time. In the second experiment the growth of the pollen tubes was slower than in the first, the tubes having passed through only the apical half of the style twenty hours after pollination. Smaller amounts of 
Table 1. Degrees curvature of individual Avena coleoptiles resulting from the application of agar blocks into which growth hormones from portions of styles and ovaries of pollinated and unpollinated flowers had diffused at different time intervals after pollination.

\begin{tabular}{|c|c|c|c|c|c|c|c|}
\hline \multirow{2}{*}{$\begin{array}{l}\text { Exp. } \\
\text { No. }\end{array}$} & \multirow{2}{*}{$\begin{array}{l}\text { Hours from } \\
\text { pollination } \\
\text { to diffusion }\end{array}$} & \multicolumn{3}{|c|}{$\begin{array}{c}\text { Unpollinated flowers } \\
\text { Style }\end{array}$} & \multicolumn{3}{|c|}{$\begin{array}{c}\text { Pollinated flowers } \\
\text { Style }\end{array}$} \\
\hline & & Apical half & Basal half & Ovary & Apical half & Basal half & Ovary \\
\hline \multirow[t]{12}{*}{1.} & 14 & 0 & 0 & 0 & 5 & 5 & 0 \\
\hline & & 0 & 0 & 0 & 4 & 5 & 5 \\
\hline & & 0 & 0 & 0 & 5 & 5 & $\mathcal{Q}$ \\
\hline & & 0 & 0 & 0 & 8 & 9 & $\mathcal{Q}$ \\
\hline & & 0 & 0 & 5 & 6 & 14 & 5 \\
\hline & & 0 & 4 & 0 & 5 & 10 & 14 \\
\hline & 42 & 0 & 0 & 0 & 1 & $\mathscr{2}$ & 18 \\
\hline & & 0 & 0 & 0 & 0 & 4 & 23 \\
\hline & & 0 & 2 & 0 & 0 & 0 & 30 \\
\hline & & 4 & 0 & 0 & 0 & 0 & 30 \\
\hline & & .. & $\ldots$ & .. & 0 & 5 & 30 \\
\hline & & . & .. & . & 0 & 1 & 33 \\
\hline \multirow[t]{12}{*}{ Q. } & 11 & .. & . & . & 4 & 6 & 0 \\
\hline & & . & $\ldots$ & $\ldots$ & 3 & 0 & 4 \\
\hline & & . & .. & . & 2 & 1 & 5 \\
\hline & & $\ldots$ & . & . & 0 & 2 & 5 \\
\hline & 20 & . & $\ldots$ & . & 7 & 1 & 2 \\
\hline & & . & . & . & 5 & 6 & 4 \\
\hline & & . & .. & .. & 2 & 5 & 6 \\
\hline & & $\ldots$ & $\ldots$ & . & 11 & 10 & 5 \\
\hline & 43 & $\ldots$ & $\ldots$ & $\ldots$ & 0 & 5 & 7 \\
\hline & & . & $\ldots$ & $\ldots$ & 0 & 3 & 10 \\
\hline & & $\ldots$ & $\ldots$ & $\ldots$ & 0 & 4 & 27 \\
\hline & & . & . & $\ldots$ & 0 & 6 & 33 \\
\hline \multirow[t]{13}{*}{3.} & 13 & .. & $\ldots$ & $\ldots$ & -6 & 5 & 0 \\
\hline & & $\ldots$ & . & $\ldots$ & 10 & 6 & 9 \\
\hline & 35 & $\ldots$ & $\ldots$ & $\ldots$ & 0 & $\ldots$ & 14 \\
\hline & & . & $\ldots$ & $\ldots$ & 0 & 3 & 17 \\
\hline & & $\ldots$ & $\ldots$ & $\ldots$ & 0 & $\mathscr{2}$ & 20 \\
\hline & 66 & $\ldots$ & $\ldots$ & $\ldots$ & 0 & 0 & 16 \\
\hline & & $\ldots$ & $\ldots$ & $\ldots$ & 0 & 0 & 20 \\
\hline & & $\ldots$ & $\ldots$ & $\ldots$ & 0 & 0 & 30 \\
\hline & & $\ldots$ & $\ldots$ & . & 0 & 0 & 33 \\
\hline & 91 & 0 & 1 & 5 & 0 & 0 & 26 \\
\hline & & $\ldots$ & $\ldots$ & $\ldots$ & 0 & 0 & 27 \\
\hline & & 0 & 0 & 6 & 0 & 3 & 28 \\
\hline & & . & $\ldots$ & $\ldots$ & 0 & 0 & 30 \\
\hline
\end{tabular}

growth hormones were obtained from the portions of styles pollinated eleven hours before the diffusion as would be expected. In all experiments the pollen tubes had grown completely through the style and entered the ovary after forty hours when fertilization may be assumed to occur. At this time the apical portions of the styles contained little, if any, growth hormones; the basal portions still had some diffusible hormone while the hormone content of the ovaries had in all except a few instances increased greatly. Poor contacts between the ovaries and agar blocks are probably responsible for the exceptions. It should be noted, however, that two other causes of variation exist in the technique which are of relatively minor importance. The coleoptiles of Avena are not all equally sensitive to the growth hormones and the pollen tube growth of different pollinations is somewhat variable.

That pollination is responsible for the presence of the growth hormones in the style and ovary of the pollinated flower is shown in two ways: first, the hormones are almost entirely absent from the style and ovary of the unpollinated flower; and second, the distribution of the growth hormones is closely related to the extent of the penetration of the pollen tubes into the style. This may be regarded as supporting the hypothesis advanced by Gustafson (1939) which states: "In normal fruits in which pollination and fertilization are necessary .... the initiation of growth of the ovary into a fruit results from the auxin brought into it by the pollen tubes." However, the critical test of the hypothesis would be 
the demonstration of hormone content in pollen grains and pollen tubes comparable to that obtained by diffusion of the pollinated styles. A number of experiments having this as their object were performed with Nicotiana, Datura, Antirrhinum and Lilium. Although excellent growth of pollen tubes in vitro was obtained, satisfactorily consistent results were not. In no instance was an amount of growth hormones obtained, by the extraction of pollen grains and pollen tubes of Nicotiana, which was equivalent to that obtained from the style of a pollinated flower by diffusion.

In evaluating these experiments it must be borne in mind that there is ample evidence to show that the diffusion method and the extraction method do not always give comparable results. It is possible that none of the methods employed here, and which are in general use for the extraction of plant growth hormones, is adequate for comparisons of such a nature.

Van Overbeek, Conklin, and Blakeslee (1941) have recently advanced the hypothesis that, since only a small amount of the total potential growth hormones is present in active form in the coleoptile tip of the seedlings of corn, a similar condition might occur in the young ovary; and "... . the diffusible substance from germinating pollen which ultimately causes enlargement of ovaries and ovules may be some prosthetic group, which, when properly combined in the ovary, forms an enzyme which activates the auxin precursor." Skoog and Thimann (1940) have reported what appeared to be the liberation of auxin from proteins of Lemna tissue by the addition of proteolytic enzymes. Wildman and Gordon (1942) have shown that auxin is associated with proteins isolated from the leaves of spinach and that the auxin can be released by enzymatic hydrolysis. It is thus possible that the growth hormones found in the style and ovary are not transferred from the pollen but are produced in situ as the result of an enzymatic hydrolysis of proteins. To restrict the contribution of the pollen tube to a prosthetic group which combines in the ovary to form an enzyme is unnecessary, for the data presented here show that the pollen tubes do not need to reach the ovary before a considerable amount of growth hormones can be obtained from the style.

Strasburger (1886) found that pollen grains of several plants could hydrolyze a starch paste to sugar, indicating diastatic activity. It was also observed that equal activity was displayed by the intact grains, by grains which discharged their contents, and by germinated pollen. Strasburger's observations were limited to the activity of pollen tubes in the case of Nicotiana for the pollen germinated readily in the starch paste medium. Paton (1921) found that in most cases the pollen tubes make their way between the cells of the style by digesting the pectin of the inner lamella with a pectinase. Testing the pollen of eighteen species, she found that all contained amylase, invertase, catalase, reductase and pectinase; pepsin, trypsin, erepsin, and lipase were demonstrated in some and not in others. The inver- tase and amylase activity of ground pollen was greater than that of unground pollen, while germinated pollen was no more active than ungerminated pollen. The amylase activity of unground germinated pollen was almost as great as that of ground germinated pollen, however. It does not seem improbable, therefore, that along with the other secretions of the pollen tubes during their penetration of the style, there is an enzyme which can release the growth hormones from whatever entities, such as proteins, they may be bound to in the inactive form.

Groweth hormones as related to flower abscission. -If pollination and fertilization do not occur, the flowers of Nicotiana wither and abscission at the base of the pedicel occurs within three to four days after the flower reaches full development. With such high concentrations of diffusible growth hormones in the fertilized ovary, it seemed probable that appreciable quantities of growth hormones would be continuously moving downward through the pedicel of the fertilized flower. Several experiments were performed to establish this as a fact. The method was essentially the same as that described above, except that only the ovary (without the style) and the pedicel were placed on the agar blocks for diffusion of the growth hormones. The receptacular enlargement of the pedicel was removel and a fresh cut was made at the base of the pedicel before the diffusion.

The curvatures obtained from these diffusions are recorded in table 2 . The diffusion in experiments 1 and 2 was into 1.5 per cent agar blocks, while that of experiment 3 was into 3 per cent agar. All were for a period of three hours. The curvatures indicate, as in the preceding experiments, that there is a marked increase in the diffusible growth hormones at the time when the pollen tubes reach the ovary (approximately thirty-five to forty hours after pollination) and at this time, or somewhat later, appreciable, and in some cases considerable, amounts of growth hormones move through the pedicel. Enlargement of the capsule begins about fifty-five hours after pollination under these conditions and larger amounts of growth hormones are present with large quantities moving through the pedicel. The unpollinated controls had no detectable quantities of growth hormones in the pedicels and only small amounts, if any, in the ovaries.

It is concluded from these experiments that the growth hormones from the ovary move through the pedicel and prevent the abscission of the flower by inhibiting the development of the absciss layer, thus allowing the ovary to develop into a fruit. Several investigators working on the abscission of leaves have shown that the growth hormones exert a definite inhibitory effect on the development of the absciss layer. Laibach (1933) found that orchid pollinia inserted in the split ends of petioles of debladed leaves of Coleus and several other plants delayed abscission of the petioles twelve to twenty days longer than in the controls. A lanolin paste containing the growth hormones from pollinia of tropical orchids also retarded abscission for eight days. LaRue (1936) ob- 
TABL: 2. Degrees curvature of individual Avena coleoptiles resulting from the application of agar blocks into which growth hormones from ovaries and pedicels of pollinated and unpollinated flowers had diffused at different time intervals after pollination.

\begin{tabular}{|c|c|c|c|c|c|}
\hline \multirow{2}{*}{$\begin{array}{l}\text { Exp. } \\
\text { No. }\end{array}$} & \multirow{2}{*}{$\begin{array}{l}\text { Hours from } \\
\text { pollination } \\
\text { to diffusion }\end{array}$} & \multicolumn{2}{|c|}{ Unpollinated flowers } & \multicolumn{2}{|c|}{ Pollinated flowers } \\
\hline & & Ovary & Pedicel & Ovary & Pedicel \\
\hline \multirow[t]{8}{*}{1.} & 17 & $\mathscr{2}$ & 0 & 1 & 0 \\
\hline & & 0 & 0 & 5 & 0 \\
\hline & & 0 & 0 & 0 & 0 \\
\hline & 39 & 4 & 0 & 12 & 8 \\
\hline & & 0 & 0 & 17 & 8 \\
\hline & 65 & 0 & 1 & 6 & 14 \\
\hline & & . & .. & 21 & 10 \\
\hline & & .. & . & 26 & 18 \\
\hline \multirow{15}{*}{2.} & 15 & 1 & 0 & 0 & 0 \\
\hline & & 0 & 0 & 2 & 0 \\
\hline & & 0 & 0 & 0 & 0 \\
\hline & 36 & 0 & 0 & 8 & 0 \\
\hline & & 2 & 0 & 9 & 1 \\
\hline & & 5 & 0 & 12 & 0 \\
\hline & 47 & 0 & 0 & 10 & 0 \\
\hline & & 2 & 0 & 18 & 2 \\
\hline & & .. & .. & 20 & 5 \\
\hline & & . & .. & 23 & 0 \\
\hline & 66 & 2 & 0 & 18 & 11 \\
\hline & & 7 & 0 & 21 & 12 \\
\hline & & .. & .. & 29 & 5 \\
\hline & 83 & .. & .. & 22 & 19 \\
\hline & & .. & .. & 32 & 6 \\
\hline \multirow[t]{15}{*}{3.} & 17 & 2 & 0 & 0 & 0 \\
\hline & & 2 & 0 & 0 & 1 \\
\hline & & 4 & 0 & 5 & 1 \\
\hline & 37 & 0 & 0 & 9 & 0 \\
\hline & & 0 & $\mathbf{0}$ & 18 & 2 \\
\hline & & 1 & 2 & 18 & 0 \\
\hline & & $\mathfrak{2}$ & 0 & 18 & 0 \\
\hline & 60 & 0 & 0 & 33 & 9 \\
\hline & & 0 & 0 & 33 & 13 \\
\hline & & 0 & 0 & 44 & 16 \\
\hline & 84 & 2 & 0 & 17 & 7 \\
\hline & & .. & .. & 23 & 9 \\
\hline & & . & .. & 28 & 10 \\
\hline & & .. & .. & 35 & 10 \\
\hline & & .. & .. & 38 & $\cdot 5$ \\
\hline
\end{tabular}

served that synthetic heteroauxin (indoleacetic acid) applied in agar or lanolin to the cut ends of petioles of Coleus and Ricinus inhibited the development of the absciss layer for significant periods of time. Similar results were obtained by Myers (1940) who also showed that growth hormones from the leaf blades influence the development of the absciss layer.

The assay of growth hormones by their diffusion into agar emphasizes the mobility they possess. It has been demonstrated that there is a continuous movement of the hormones down the pedicel, while at the same time an approximately uniform concentration of diffusible growth hormones is maintained in the ovary for at least fifty hours after fertilization. That this production and movement of hor- mones out of the ovary over an extended period of time is important for continued growth of the fruit is indicated by the results of investigations of Gardner and Marth (1937). They found that spraying flowers of Ilex opaca witl indoleacetic, indolebutyric, indolepropionic, and naphthaleneacetic acids caused fruit set without pollination. However, when a second flush of growth occurred in both pollinated and sprayed plants, the sprayed plants dropped all of their fruit, while none of the pollinated plants dropped their fruit. Gardner and Marth regarded the lack of abscission in the case of the pollinated fruits as probably associated with the development of the embryos within their seeds. That conclusion is substantiated here in so far as fertilization is re- 
sponsible for a continuous movement of growth hormones, released in the fruit, through the pedicel.

Another important aspect of the movement of the growth hormones out of the ovary is the part the hormones would have in the development of the conducting elements in the pedicel and other portions of the inflorescence, providing for the movement of food materials into the growing ovary. This development in Ilex opaca, according to Gardner and Kraus (1937), is mainly a matter of maturation with only a few additional elements being differentiated from the cambium.

\section{SUMMARY}

Direct measurements of diffusible growth hormones were made on styles and ovaries of pollinated and unpollinated flowers of Nicotiana tabacum. None or very small amounts were obtained from the portions of an unpollinated pistil, but considerable quantities were found in the portions of a pollinated pistil. The growth hormone concentration was close- ly related to the extent of the penetration of the pollen tubes into the style - fertilization resulting in the release of large amounts in the ovary.

The data are considered in relation to the hypotheses advanced to explain the initiation of fruit development by pollination. The extraction of pollen grains and pollen tubes did not indicate them to be the source of the growth hormones. It is suggested that the pollen tubes may secrete an enzyme which can liberate the growth hormones from inactive combinations in the style and ovary.

The growth hormones released in the fertilized ovary move downward through the pedicel and prevent abscission of the pistil by inhibiting the development of the absciss layer. These hormones are also probably concerned in the development of the conducting elements through which food materials move into the growing ovary.

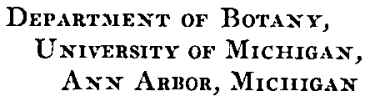

Departaeyt of Botayy, University of Michigan, Axy Arbor, Micingay

\section{LITERATURE CITED}

Bucrmolz, J. T. 1931. The dissection, staining and mounting of styles in the study of pollen-tube distribution. Stain Technology. 6:13-24.

Gustafsox, F. G. 1936. Inducement of fruit development by growth-promoting chemicals. Proc. Nat. Acad. Sci. U. S. A. $22: 628-636$.

—. 1937. Parthenocarpy induced by pollen extracts. Amer. Jour. Bot. 24: 102-107.

-. 1939. Auxin distribution in fruits and its significance in fruit development. Amer. Jour. Bot. 26: 189-194.

GardNer, F. E., and E. J. KRAUS. 1937. Histological comparison of fruits developing parthenocarpically and following pollination. Bot. Gaz. 99:355-376.

_- and P. C. Mantr. 1937. Parthenocarpic fruits induced by spraying with growth promoting compounds. Bot. Gaz. 99: 184-195.

Laibach, F. 1932. Pollenhormon und Wuchsstoff. Ber. Deutsch. Bot. Ges. 50: 383-390.

—. 1933. Wuchsstoffversuche mit lebenden Orchideenpollinien. Ber. Deutsch. Bot. Ges. 51:336-340. . 1933. Versuche mit Wuchsstoffpaste. Ber. Deutsch. Bot. Ges. 51: 386-392.

LARve, C. D. 1936. The effect of auxin on the abscission of petioles. Proc. Nat. Acad. Sci. U. S. A. 22:254-259.

MYers, R. M. 1940. Effect of growth substances on the absciss layer in leaves of Coleus. Bot. Gaz. 102: 323338.

Overheek, J. Vay, M. E. Coykin, axp A. F. Brakeslee. 1941. Chemical stimulation of ovule development and its possible relation to parthenogenesis. Amer. Jour. Bot. 28: 6+7-656.

Patox, J. B. 1921. Pollen and pollen enzymes. Amer. Jour. Bot. 8: 471-s01.

Skoog, F. 1937. A deseeded Avena test method for small amounts of auxin and auxin precursors. Jour. Gen. Physiol. 20:311-334.

——, AND K. V. Thrmasy, 1940. Enzymatic liberation of auxin from plant tissues. Science 92:64.

Strasbungen, E. 1886. Ueber fremdartige Bestäubung. Jahrb. Wiss. Bot. $17: 50-98$.

West, F. W. 1928. Wuchstoff und Wachstum. Recueil Trav. Bot. Néerland 25: 1-116.

- avd K. V. Timmays. 1937. Phytohormones. New York.

Wilduan, S. G., axd S. A. Gornow. 1942. The release of auxin from isolated leaf proteins of spinach. Proc. Nat. Acad. Sci. U. S. A. (In press.) 